\title{
DL-Methadone as an Enhancer of Chemotherapeutic Drugs in Head and Neck Cancer Cell Lines
}

\author{
VERONIKA LANDGRAF, MATTHIAS GRIESSMANN, JEANETTE ROLLER, \\ CHRISTINE POLEDNIK and MARIANNE SCHMIDT
}

Department of Otorhinolaryngology, University of Wuerzburg, Wuerzburg, Germany

\begin{abstract}
Background/Aim: The aim of this study was to analyze the effect of DL-methadone on enhancing the action of the chemotherapeutic drugs cisplatin, doxorubicin, 5-fluoruracil (5-FU) and paclitaxel on head and neck squamous carcinoma (HNSCC) cell lines. Materials and Methods: The chemotherapeutic drugs were applied alone or in combination with DL-methadone and cytotoxicity was analyzed by XTT assays. Expression of the $\mu$-opioid receptor and the drug transporter p-glycoprotein were analyzed by $q R T$ PCR. Results: The effect of DL-methadone strongly depended on the respective chemotherapeutic agent. The basic expression of the $\mu$-opioid receptor was not associated with the effect of DL-methadone, rather its induction by chemotherapeutic drugs. Expression or expression induction of p-glycoprotein was higher in weak-responder cell lines. Conclusion: Enhancement of the toxicity of chemotherapeutic drugs by $D L$ methadone depends on the drug and on the cell line used.
\end{abstract}

According to the survey by Guntinas-Lichius (1), who has analyzed the epidemiology and prognosis of head and neck squamous cancer (HNSCC) in Germany, the incidence of head and neck subsites have changed between 1996 and 2005. Although multimodal treatment strategies have been developed and applied to patients, the outcome has not been improved significantly within this time span (1). Surgical resection of the tumor remains the first choice of treatment. However, in many cases of locally advanced HNSCC this therapy option is not suitable. Many organs in the facial and neck region are functionally compromised (such as swallowing, breathing, speaking). Combined radiochemotherapy has become a standard approach in these

Correspondence to: Marianne Schmidt, Department of Otorhinolaryngology, University of Wuerzburg, Josef-SchneiderStraße 11, D-97080 Wuerzburg, Germany. Tel: +49 93120121365 , Fax: +49 93120121166, e-mail: Schmidt_m2@ukw.de

Key Words: Opioid receptor, methadone, chemotherapy, carcinoma, head and neck, metastasis, HNSCC, gene expression. cases (2). For this reason, there is still a demand for new treatment approaches in head and neck cancer.

The synthetic opioid DL-methadone is primarily known as a maintenance drug in heroin addicts. However, it is also widely used in palliative management of cancer pain (3), offering advantages, like a long half-life and mucosal resorption, indispensable in patients with dysphagia (4). During the last years a new feature of methadone has become apparent. Friesen et al., have described a chemo-sensitising action of methadone in tumour cells of different origins (57). The action of methadone as a "chemo-enhancer" involves signalling through the $\mu$-type opioid receptor and a subsequent G-protein coupled depletion of cAMP, initiating the intrinsic (or mitochondrial) apoptotic pathway including caspase 9 and 3 cleavage. Furthermore, an increased uptake of toxic agents and decreased detoxification via the ABCtransporter p-glycoprotein seem to play an important role (7). The results of Friesen's group became quite popular, especially after a TV presentation in Germany, and many patients demanded methadone from their physicians for combination treatment. Meanwhile a harsh headwind was developed, doubting the benefit of methadone combination treatment and demanding clinical trials first.

Meanwhile a few investigations about the in vitro action of methadone in combination with different chemotherapeutics have been published with different results for melanoma (8), bladder cancer (9) and prostate cancer (10).

In this study, the chemo-sensitizing effect of DLmethadone in combination with the chemotherapeutics cisplatin, doxorubicin, 5-FU and paclitaxel was investigated in a panel of HNSCC cell lines.

\section{Materials and Methods}

Reagents. DL-methadone hydrochloride (Sigma Aldrich, Munich, Germany) was freshly prepared for each experiment as a $32 \mu \mathrm{M}$ stock solution. L-Methadone (L-Polamidon, Aventis-Sanofi, Frankfurt, Germany) was used as a ready to use injection solution at $32 \mu \mathrm{M}$. The chemotherapeutics cisplatin, doxorubicin, 5-fluoruracil (5-FU), paclitaxel were obtained from the Pharmacy of the University hospital of Wuerzburg. 
FADU

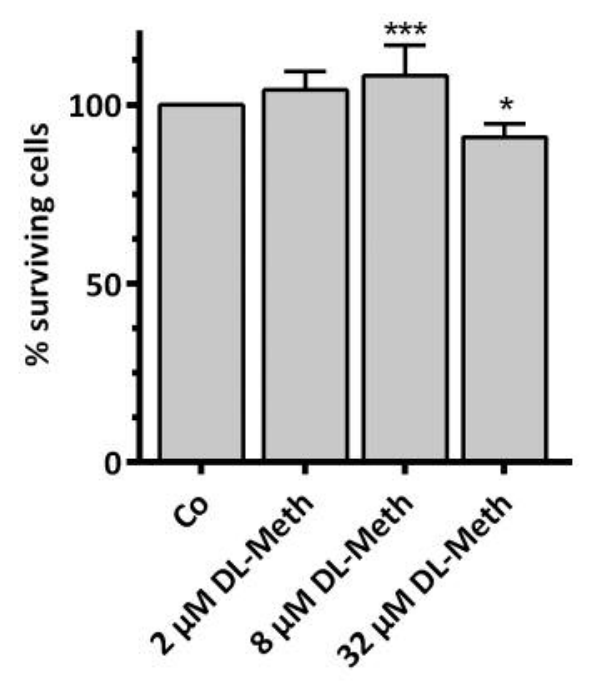

PE/CA-PJ41

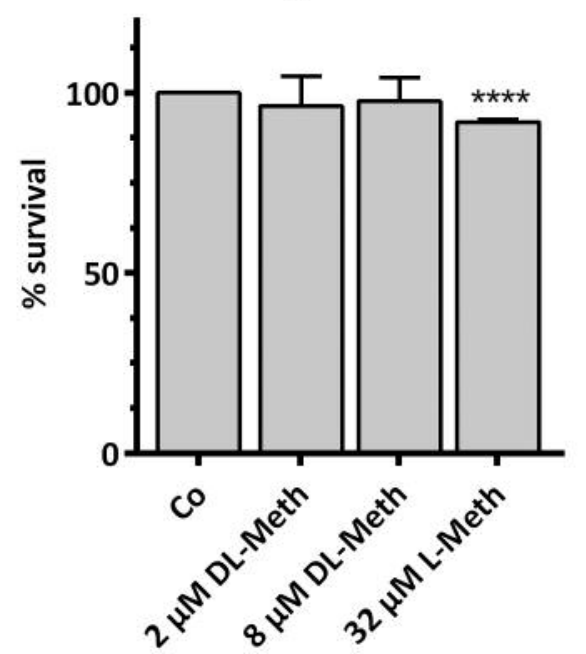

HLaC78

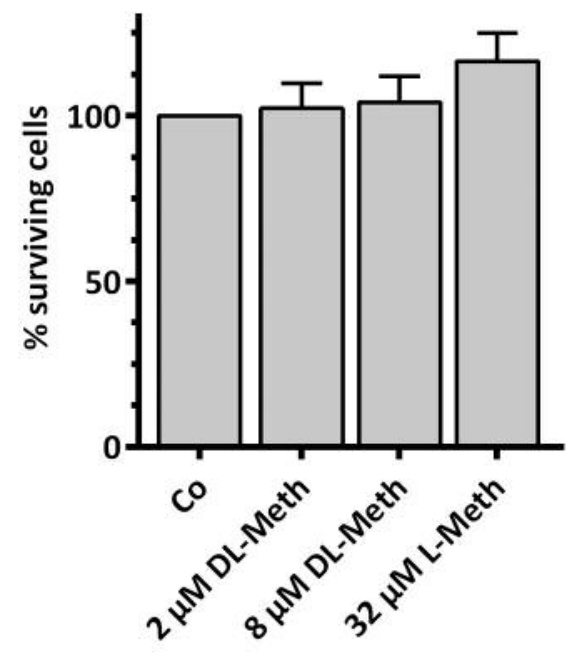

A172

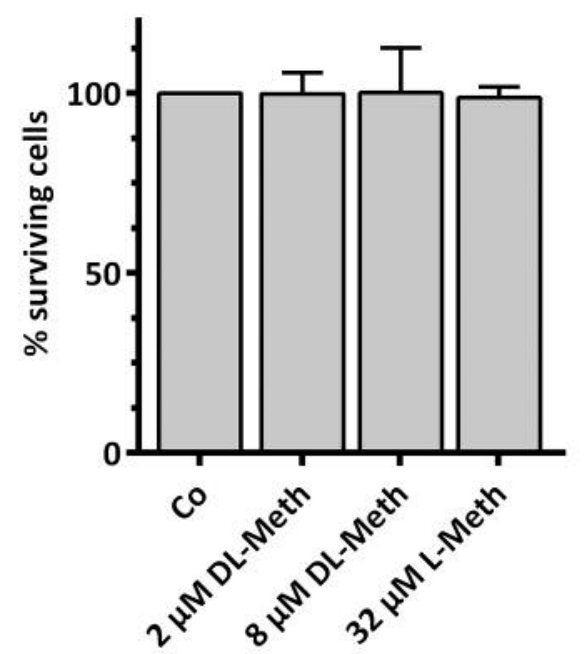

Figure 1. Cytotoxicity of increasing concentrations of DL-methadone on HNSCC cell lines HLaC78, FADU, PE/CA-PJ41 and the glioblastoma cell line A172 as measured with the XTT assay. Data are presented as the mean of 3 independent experiments \pm standard deviation.

Cell lines and cell culture. The cell line FADU originating from a hypopharyngeal carcinoma was grown in RPMI 1640 medium (Seromed, Munich, Germany), supplemented with $10 \%$ foetal bovine serum (FBS). HLaC78 cell line derived from larynx carcinoma (11) was grown in RPMI 1640 medium. The oral carcinoma derived cell line PE/CA-PJ41 was cultured in RPMI 1640 medium with $10 \%$ FBS. As a reference cell line for methadone treatment the glioblastoma derived cell line A172 (CLS, Eppelheim, Germany) was used. It was grown in DMEM medium supplemented with $10 \%$ FBS.

Cell viability and proliferation assay. The XTT Cell Proliferation Assay was used to measure the cell proliferation rate and the reduction in cell viability induced by the addition of chemotherapeutic drugs and methadone. A total of 3,000 cells were seeded in cell culture medium in 96-well plates with or without the $\mathrm{EC}_{50}$ concentration of cytostatic drugs and with or without methadone (either 2, 8 or $32 \mu \mathrm{M}$ DL-methadone) and incubated for $48 \mathrm{~h}$. After a $48 \mathrm{~h}$ incubation period, the culture medium was replaced by $125 \mu \mathrm{l}$ XTT solution per well $(0,2 \mathrm{mg} / \mathrm{ml}$ XTT and 10 $\mu \mathrm{M}$ Phenazine methosulfate). Cells were incubated for $2 \mathrm{~h}$ at $37^{\circ} \mathrm{C}$ and subsequently the absorbance was measured at $450 \mathrm{~nm}$ with a microplate reader. The experiments were repeated three times independently.

$\mathrm{EC}_{50}$ concentrations used for each cell line are summarized in Table I. Control wells were treated with vehicle. Relative toxicity was calculated as a $\%$ of surviving cells by setting solvent treated control cells as $100 \%$. 
FADU DL-Methadone + cytostatic drugs

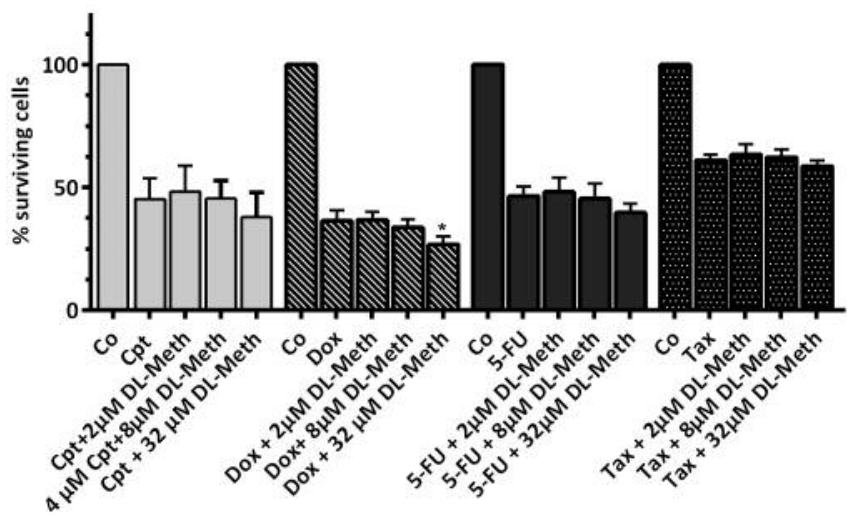

PJ41 DL-Methadon+ cytostatic drugs
HLaC78 DL-Methadone + cytostatic drugs

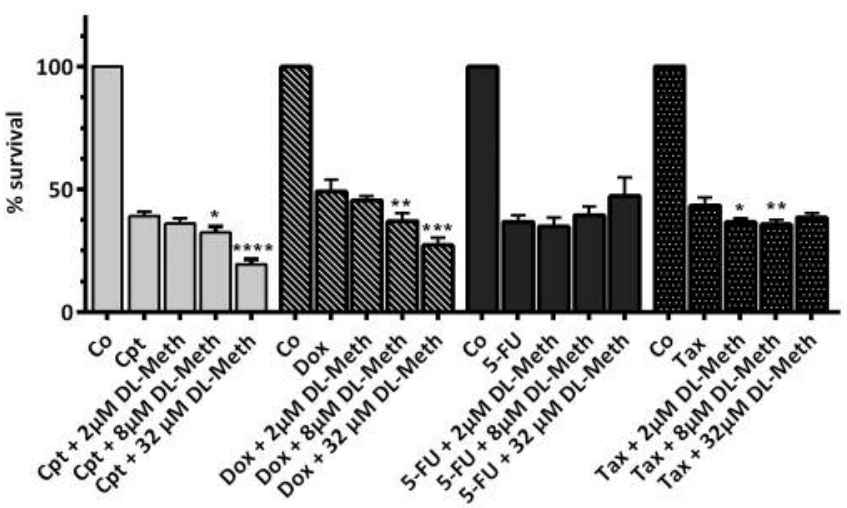

A172 DL-Methadone + cytostatic drugs
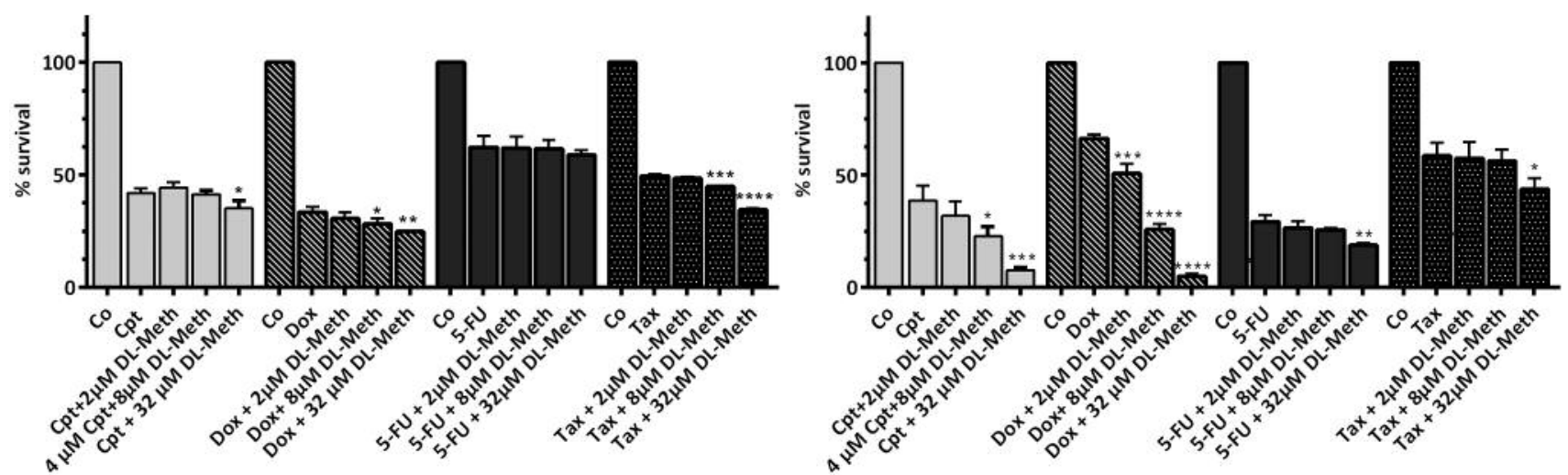

Figure 2. Cytotoxicity of increasing concentrations of DL-methadone (DL-Meth) on HNSCC cell lines HLaC78, FADU, PE/CA-PJ41 and the glioblastoma cell line A172 in combination with the cytostatic drugs cisplatin (cpt), doxorubicin (dox), 5-fluoruracil (5-FU) or paclitaxel (tax) as measured with the XTT assay. Data are presented as the mean of 3 independent experiments \pm standard deviation.

RNA extraction and RNA quality control. RNA of HNSCC cell cultures was isolated with the RNeasy kit (Qiagen, Hilden, Germany) according to the manufacturer's instructions. Purity and concentration were determined photometrically.

Taqman real time PCR. In order to analyse the expression of the $\mu$-opioid receptor and the drug transporter p-glycoprotein (OPRM1 and MDR-1) Taqman real-time PCR was used. RNA was isolated (see above) and real-time TaqmanR PCR (AppliedBiosystems.com) was performed in triplicates on a real-time PCR cycler (Applied Biosytems, Darmstadt, Germany) using the Taqman gene expression assay for CYP1A1. Relative quantification was calculated according to the $2^{-\Delta \Delta C T}$ method (12). Expression values were normalized to the expression of GAPDH as an endogenous control.

Statistical analysis. All statistical analyses and graphs were performed with Graph Pad Prism 6 (Graphpad Software, La Jolla, USA). Data are presented as the mean of three independent
Table I. EC 50 concentrations of cytostatic drugs determined by XTT assay.

\begin{tabular}{lrccc}
\hline $\mathrm{EC}_{50}$ values & $\mathrm{FaDu}$ & $\mathrm{HLaC} 78$ & $\mathrm{PE} / \mathrm{CA}-\mathrm{PJ} 41$ & $\mathrm{~A} 172$ \\
\hline Cisplatin $[\mu \mathrm{M}]$ & 3.5 & 2.75 & 4.5 & 60 \\
Doxorubicin $[\mathrm{nM}]$ & 150 & 160 & 100 & 185 \\
5-Fluoruracil $[\mu \mathrm{M}]$ & 25 & 15 & 20 & 500 \\
Paclitaxel $[\mathrm{nM}]$ & 18.5 & 7 & 20 & 85 \\
\hline
\end{tabular}

experiments or eight measured spheroids \pm standard deviation. Unpaired t-test (angiogenesis, migration measurements) or ANOVA Dunnett's multiple comparison test (qRT-PCR) were used for statistical analysis. Differences were considered to be significant at $* * * * p<0.0001, * * * p<0.001, * * p<0.01, * p<0.05$. 


\section{Results}

Cytotoxicity. The HNSCC cell lines FADU, HLaC78, PE/CA-PJ41, HLaC79 and HLaC79-Tax, as well as the glioblastoma cell line A172 were incubated with DLmethadone or L-methadone at 2,8 or $32 \mu \mathrm{M}$ for $48 \mathrm{~h}$ in order to analyse the potential toxic effects on HNSCC. The XTT assay was used to measure cell viability and cytotoxicity (Figure 1). For the calculation of inhibition rates at least three independent experiments were carried out.

In PE/CA-PJ41 and FaDu, a slight, but significant decrease in viability was reached with DL-methadone after $48 \mathrm{~h}$ at a dose of $32 \mu \mathrm{M}$. While the viability of the glioblastoma cell line A172 was not influenced by DL-methadone, growth stimulation was observed in $\mathrm{FaDu}$ and $\mathrm{HLaC} 78$ cells.

Combining DL-methadone with the chemotherapeutics cisplatin (Cpt), doxorubicin (dox), 5-FU and paclitaxel (Tax) at their $\mathrm{EC}_{50}$ concentrations increased the sensitivity of cells to the chemotherapeutic drugs: however, the response rates varied between the cell lines. The results of the growth inhibition analyses are summarized in Figure 2.

XTT assays revealed striking differences among the different cell lines. Generally, all HNSCC cell lines were less susceptible to chemo-sensitisation by DL-methadone compared to the glioblastoma cell line A172. Treatment of A172 with physiological concentrations DL-methadone resulted in significant chemo-sensitization upon combination with doxorubicin and cisplatin. Significant chemosensitization was also observed upon combination of paclitaxel with $32 \mu \mathrm{M}$ DL-methadone. The cell line FaDu did not respond to DL-methadone. Combination of $32 \mu \mathrm{M}$ DL-methadone with doxorubicin enhanced toxicity of doxorubicin. HLaC78 and PE-CA-PJ41cells were intermediate responders. Both showed chemo-sensitisation towards cisplatin, doxorubicin and paclitaxel with low DLmethadone concentrations. DL-methadone did not provoke a significant sensitisation towards 5-FU in any of the cell lines tested. Interestingly, in $\mathrm{HLaC} 78$ the combination of 5-FU and DL-methadone stimulated the growth of the cells.

Expression of OPRM1. Taking the role of the $\mu$-type opioid receptor (OPRM1) into account, the expression levels of OPRM1 were investigated by quantitative reverse transcription PCR (qRT-PCR). Results are displayed in Figure 3.

Interestingly both $\mathrm{A} 172$ and $\mathrm{FaDu}$ cells, which differ enormously in their susceptibility towards DL-methadone chemo-sensitisation showed similar low basic levels of OPRM1 expression. For this reason, expression of OPRM1 was analysed in response to the chemotherapeutic drugs cisplatin, doxorubicin, 5-FU and paclitaxel. Results are shown in Figure 4.

Here, $\mathrm{FaDu}$ and $\mathrm{A} 172$ cells also showed similar expression changes in response to drug treatment. Treatment

\section{OPRM1}

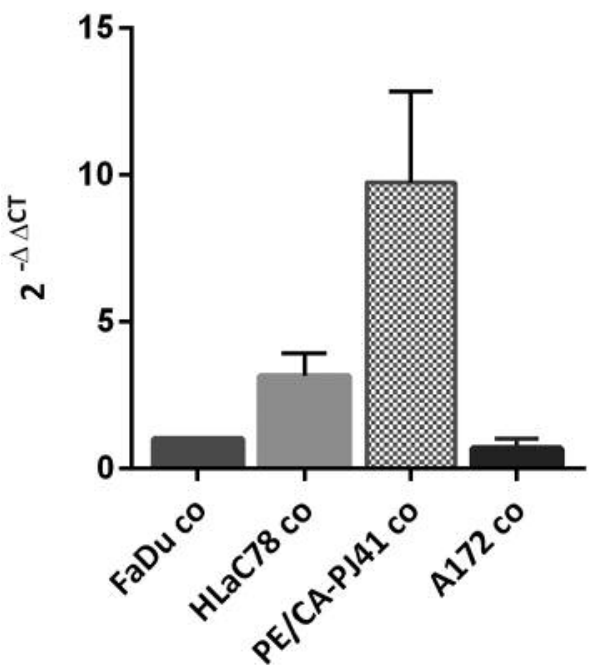

Figure 3. TaqMan RT-PCR analysis for basic expression of the $\mu$-type opioid receptor (OPRM1) in the cell lines FaDu, HLaC78, PE/CA$P J 41$, and A172. Values are presented as mean \pm standard deviation.

with doxorubicin increased OPRM1 expression in both cell lines (FaDu 6.6-fold, A172 7-fold). None of the other drugs changed the expression of OPRM1 significantly in these two cell lines. Nevertheless, FaDu and A172 cells largely differ in their susceptibility to chemo-sensitisation by DLmethadone. Thus, the levels of OPRM1 expression do not seem to play a major role in chemo-sensitisation: While PE/CA-PJ41 cells showed the highest basic expression of OPRM1, which was even down-regulated by doxorubicin, a weak but significant enhancement of doxorubicin toxicity could be observed at $8 \mathrm{mM}$ DL-methadone. Furthermore, in A172 cells, OPRM1 was up-regulated only by doxorubicin. However, treatment of A172 cells with DL-methadone enhanced cisplatin-induced toxicity.

HLaC78 cells, the strongest DL-methadone responder HNSCC cell line, showed a significant up-regulation of OPRM1 following treatment with doxorubicin, cisplatin or paclitaxel.

Due to the finding, that p-glycoprotein (MDR1) plays a role in the effects of DL-methadone on doxorubicin detoxification (7) and to provide an explanation for the differential sensitivity of the HNSCC cell lines towards DLmethadone, the expression of the cancer-related drug transporter p-glycoprotein (ABCB1) was analysed by qRTPCR. Results are displayed in Figure 5.

The graphical plot of MDR-1 expression shows likewise the highest basic expression of the p-glycoprotein gene in CA/PEPJ41 cells. Although MDR-1 expression significantly increases in most cell lines after $48 \mathrm{~h}$ drug exposure, the 


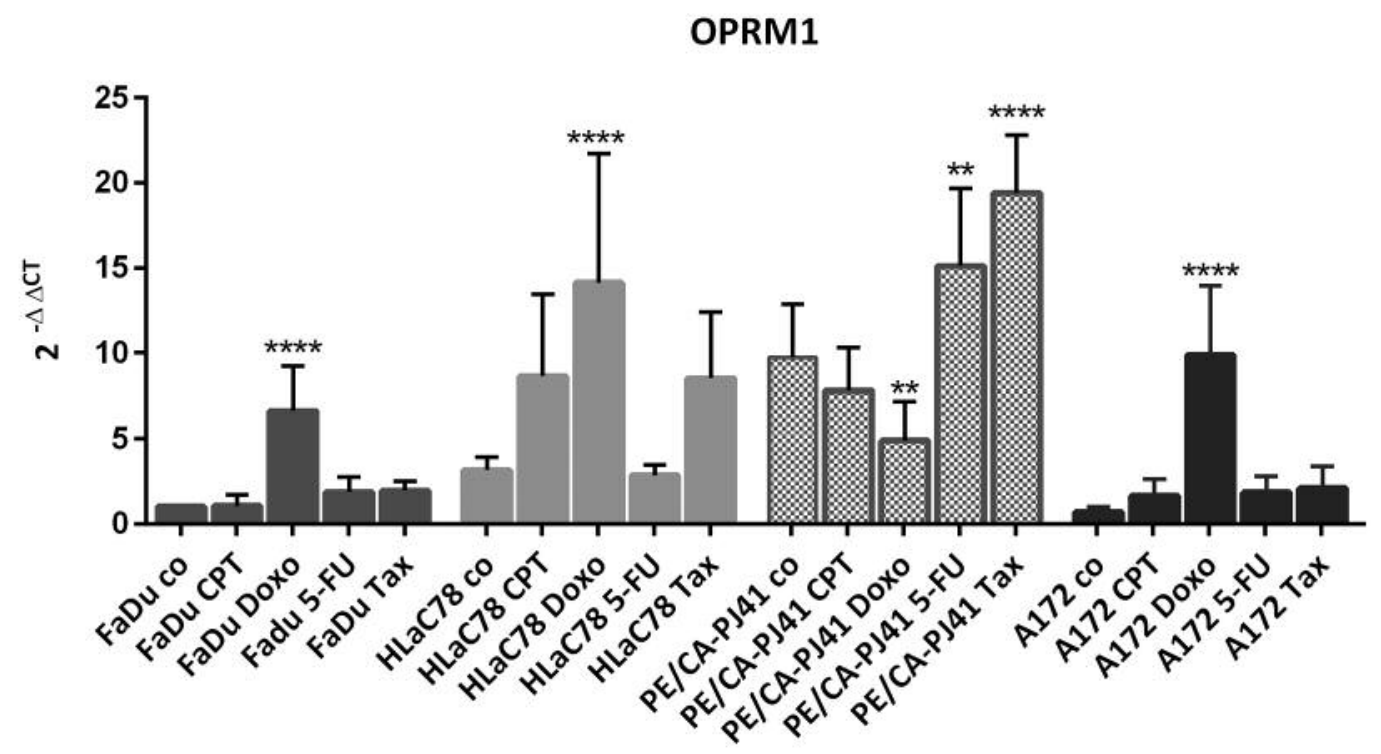

Figure 4. TaqMan RT-PCR analysis for the $\mu$-opioid receptor OPRM1 in the cell lines FaDu, HLaC78, PE/CA-PJ41, and A172, treated with the chemotherapeutics cisplatin (cpt), doxorubicin (dox), 5-fluoruracile (5-FU) or paclitaxel (tax). Gene expression was measured following $48 \mathrm{~h}$ incubation of cell lines with $E_{50}$ concentrations of each substance alone or in combination with 2,8 or $32 \mu M$ DL-methadone. Values are presented as mean \pm standard deviation. Fold changes were compared within each group (cell line) in relation to the untreated control cells (co) $* * * * p<0.0001$, $*_{* *}^{*}<0.001, * * p<0.01 ;$ statistically significant values; ANOVA Dunnett's multiple comparison test.

\section{MDR1}

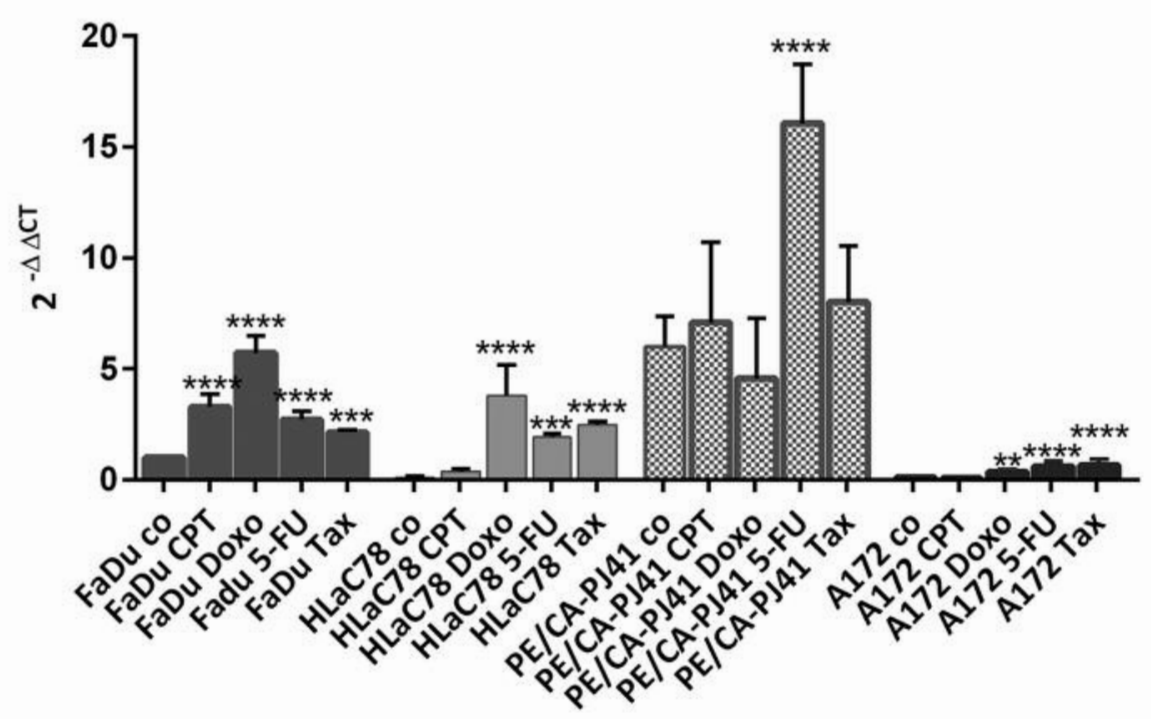

Figure 5. TaqMan RT-PCR analysis for the ABC transporter MDR1 in the cell lines FaDu, HLaC78, PE/CA-PJ41, and A172, treated with the chemotherapeutics cisplatin (cpt), doxorubicin (dox), 5-fluoruracile (5-FU) or paclitaxel (tax). Gene expression was measured following $48 \mathrm{~h}$ incubation of cell lines with $E C_{50}$ concentrations of each substance alone or in combination with 2,8 or $32 \mu M$ DL-methadone. Values are presented as mean \pm standard deviation. Fold changes were compared within each group (cell line) in relation to the untreated control cells (co) $* * * * p<0.0001$, $* * * p<0.001, * * p<0.01$; statistically significant values; ANOVA Dunnett's multiple comparison test.

overall expression differs widely between cell lines. Especially the direct comparison of $\mathrm{FaDu}$ and $\mathrm{A} 172$ cells showed a noticeable difference: While A172 cells maintained a low to moderate expression level of MDR-1 in response to all drugs tested, in $\mathrm{FaDu}$ cells expression of the ABC-transporter was significantly up-regulated upon drug exposure. 


\section{Discussion}

DL-methadone and L-methadone have been used to analyse chemosensitization to chemotherapeutic drugs in diverse tumour systems, such as glioblastoma (5), leukemia (6) or bladder carcinoma (9). As chemotherapeutic drugs doxorubicin $(5,6)$, cisplatin (9) or Temozolomide (13) have been used. The present study is the first to analyse the effect of DL-methadone on head and neck carcinoma cell lines alone or in combination with cytostatic drugs. The panel of chemotherapeutics was expanded to include paclitaxel and 5fluoruracil (5-FU). As a classical "responder" cell line, i.e. a cell line with known enhancement of doxorubicin toxicity by DL-methadone, the glioblastoma cell line A172 was included. DL-methadone showed no toxicity in any of the cell lines examined. This is in agreement with Michalska et al. (9), who have examined the effect of several concentrations of DLmethadone on bladder cancer cell lines. Viability assays with varying combinations of chemotherapeutics revealed, that it depends on the chemotherapeutic drug combined with DLmethadone: while doxorubicin-induced toxicity was significantly enhanced, the toxicity of 5-FU was not enhanced in any of the cell lines used. Sensitisation towards cisplatin or paclitaxel was cell-type dependent. While DL-methadone enhanced the toxicity of doxorubicin or cisplatin in HLaC78 cells, no enhancement of the toxicity of any of the drugs used was observed in FaDu cells. DL-methadone showed the strongest enhancement effect in doxorubicin-treated A172 cells compared to all other HNSCC cell lines. These results agree with those of Michalska et al. (9), who have also reported "responder" and "non-responder" cell lines among the bladder cancer cell lines tested in their study. Concerning the role of the $\mu$-type opioid receptor it seems likely, that the basic expression is not decisive for the chemo-enhancing effect of DL-methadone, since A172 cells had the lowest expression level of OPRM1. It is rather likely, that induction of the expression of the receptor by the chemotherapeutics may play a role. Latzer et al. (13) have shown that treatment of several glioblastoma cell lines with L-methadone resulted in weak enhancement of toxicity of temozolomide, the standard chemotherapeutic drug for glioblastoma treatment. They analysed the expression of the $\mu$-opioid-receptor in patients' tumour tissue and found expression only in few cells of the tissue and concluded, that DL-methadone is not suitable for glioblastoma patients. This might be a fallacy in two ways. First, it seems that the basic expression of OPRM1 is not important and second, the combination of methadone with other chemotherapeutics, such as liposomal doxorubicin (which has already been tested in phase II trials) might be more successful. Nevertheless, the question why the HNSCC cell line $\mathrm{FaDu}$ is a non-responder still remains.

A difference between the non-responder cell line $\mathrm{FaDu}$ and the responder cell line A172 appeared, when the expression of MDR-1, which codes for the ABC transporter p-glycoprotein was considered: While both untreated and drug-treated A172 cells expressed only low levels of MDR1, MDR-1 transcription was enhanced by chemotherapeutic drugs in FaDu cells.

Possibly a certain balance of $\mu$-opioid-receptor induction and detoxification capacity is necessary to reveal an enhancement of chemotherapy in combination with DLmethadone. Future experiments have to analyse the role of other drug transporters, such as breast cancer related antigen (BRCA), MRP-1 and MRP-2. In addition, detailed analysis of apoptosis has to be carried out.

In summary, it seems likely, that the enhancement of cytotoxicity of chemotherapeutic drugs by DL-methadone depends on the drug used for treatment and also on the cell line tested (responder and non-responder cell lines). The basic expression of the $\mu$-opioid-receptor seems to play a minor role, it is more likely, that the induction of expression by the chemotherapeutic drug is more important. Furthermore, the expression of drug transporters upon drug treatment might have an influence on the susceptibility of a cell line towards DL-methadone.

\section{Conflicts of Interest}

The Authors declare that there are no conflicts of interest

\section{Authors' Contributions}

VL performed most of the cell culture and PCR experiments and performed statistical analyses. $\mathrm{MG}$ determined the $\mathrm{EC}_{50}$ concentrations of the cytotoxic drugs. CP assisted in cell culture. JR assisted in qRT-PCR experiments. MS evaluated data and wrote the manuscript.

\section{References}

1 Guntinas-Lichius O, Wendt T, Buentzel J, Esser D, Lochner P, Mueller A, Schultze-Mosgau S and Altendorf-Hofmann A: Head and neck cancer in germany: A site-specific analysis of survival of the thuringian cancer registration database. J Cancer Res Clin Oncol 136(1): 55-63, 2010. PMID: 19568769. DOI: 10.1007/ s00432-009-0636-y

2 Winquist E, Agbassi C, Meyers BM, Yoo J, Chan KKW and Head and Neck Disease Site Group: Systemic therapy in the curative treatment of head and neck squamous cell cancer: A systematic review. J Otolaryngol Head Neck Surg 46(1): 29, 2017. PMID: 28376866. DOI: 10.1186/s40463-017-0199-x

3 Mercadante S and Bruera E: Methadone as a first-line opioid in cancer pain management: A systematic review. J Pain Symptom Manage 55(3): 998-1003, 2018. PMID: 29101087. DOI: 10.1016/j.jpainsymman.2017.10.017

4 Hawley P, Wing P and Nayar S: Methadone for pain: What to do when the oral route is not available. J Pain Symptom Manage 49(6): e4-6, 2015. PMID: 25849861. DOI: 10.1016/j.jpainsy mman.2015.03.006 
5 Friesen C, Hormann I, Roscher M, Fichtner I, Alt A, Hilger R, Debatin KM and Miltner E: Opioid receptor activation triggering downregulation of camp improves effectiveness of anti-cancer drugs in treatment of glioblastoma. Cell Cycle 13(10): 15601570, 2014. PMID: 24626197. DOI: 10.4161/cc.28493

6 Friesen C, Roscher M, Alt A and Miltner E: Methadone, commonly used as maintenance medication for outpatient treatment of opioid dependence, kills leukemia cells and overcomes chemoresistance. Cancer Res 68(15): 6059-6064, 2008. PMID: 18676827. DOI 10.1158/0008-5472.CAN-08-1227

7 Friesen C, Roscher M, Hormann I, Fichtner I, Alt A, Hilger RA, Debatin KM and Miltner E: Cell death sensitization of leukemia cells by opioid receptor activation. Oncotarget 4(5): 677-690, 2013. PMID: 23633472. DOI: 10.18632/oncotarget.952

8 Bruggen MC, Mangana J, Irmisch A, French LE, Levesque MP, Cheng PF and Dummer R: Methadone-not a magic bullet in melanoma therapy. Exp Dermatol 27(6): 694-696, 2018. PMID: 29577418. DOI: $10.1111 /$ exd.13543

9 Michalska M, Schultze-Seemann S, Kuckuck I, Katzenwadel A and Wolf P: Impact of methadone on cisplatin treatment of bladder cancer cells. Anticancer Res 38(3): 1369-1375, 2018. PMID: 29491061. DOI: 10.21873/anticanres.12360
10 Stadlbauer B, Kozian D, Stief C and Buchner A: MP83-19 Cotreatment with 1-methadone significantlyincreases the efficacy of cytostatic drugs in prostate cancer cells. J Urol 197(4S Suppl): e1114, 2017.

11 Zenner HP, Lehner W and Herrmann IF: Establishment of carcinoma cell lines from larynx and submandibular gland. Arch Otorhinolaryngol 225(4): 269-277, 1979. PMID: 548013.

12 Livak KJ and Schmittgen TD: Analysis of relative gene expression data using real-time quantitative pcr and the 2(-delta delta $\mathrm{c}(\mathrm{t})$ ) method. Methods 25(4): 402-408, 2001. PMID: 11846609. DOI: $10.1006 /$ meth.2001.1262

13 Latzer P, Kessler T, SahmF, Rübmann P, Hielscher T, Platten M and Wick W: P04.30 Methadone does not increase toxicity of temozolomide in glioblastoma cells. Oncol Res Treat 41(suppl 1): 1-221, 2018. DOI: 10.1093/neuonc/noy139.264

Received March 22, 2019

Revised June 14, 2019

Accepted June 18, 2019 